\title{
Effects of dietary supplements of newly growing heather on the breeding of captive red grouse
}

\author{
By R. MOSS, A. WATSON, R. PARR AND W. GLENNIE \\ Nature Conservancy, Blackhall, Banchory, Kincardineshire
}

(Received I6 April 1970-Accepted I4 August I970)

\begin{abstract}
I. The effects of dietary supplements of heather at different stages of growth on the breeding of captive red grouse were studied.

2. A supplement of heather which was beginning to grow in spring stimulated captive red grouse to lay more eggs and to lay at a faster rate than birds given a supplement of dormant winter heather.

3. Although laying was stimulated, no significant effect on the date of laying, the hatchability of the eggs or the survival of the young was demonstrated; however, the possibility of such effects occurring in the wild is not ruled out.

4. The experimental effect occurred although the heather formed only a small proportion of a largely artificial diet, which provided a high plane of nutrition in terms of known nutrients.

5. The effect is attributed to an unidentified factor contained in the new growth.
\end{abstract}

The aim of this paper is to show that freshly growing heather (Calluna vulgaris [L.] Hull) may stimulate the breeding of red grouse (Lagopus lagopus scoticus [Lath.]) independently of their plane of nutrition.

Wild red grouse in north-east Scotland generally lay their eggs in late April or early May. At this time the heather, which is their main food plant (Wilson, I9I I J Jenkins, Watson \& Miller, 1963; Eastman, 1964), is just beginning to grow. Frequently, though not always, early heather growth is followed by early and successful grouse breeding, and late heather growth by later and poorer breeding (Jenkins, Watson \& Miller, I967). Breeding success bears little relation to summer weather after the chicks hatch (Jenkins et al. 1963, 1967). Size of clutch and hatchability vary from year to year but fluctuations in the number of young that reach adult size are due mainly to larger variations in the survival of the chicks.

Chick survival appears to be determined partly by the quality of the eggs laid (Jenkins, Watson \& Picozzi, 1965), which may, in turn, be influenced by the nutritive value of the diet eaten by the hens before and during laying. The content of both protein and phosphorus is low in spring heather (Moss, 1967), although higher than in winter heather, and the nutritive value of the birds' diet is probably determined in part by the amount of these nutrients in the heather. This in turn is influenced by the stage of growth reached by the plant. Thus, breeding in wild red grouse may be affected by the weather in spring, through its subsequent effects on their nutrition.

However, the experiment described in this paper was designed to rule out nutritional effects as far as possible by feeding captive birds at a high plane of nutrition. A small supplement of freshly growing spring heather was added to the diet of one group and a similar amount of dormant winter heather to that of a second group, to see if the growing vegetation had any effect on the birds' breeding. 


\section{EXPERIMENTAL}

\section{Grouse}

The grouse in these experiments were derived largely from chicks caught on Kerloch moor, Kincardineshire, in summer I $96_{3}$, and from grouse hatched from wild birds' eggs collected on various moors before r 963 . From r 964 onwards, most of the birds reared were from eggs laid in captivity and a few were from wild birds' eggs collected in each year.

Birds were housed in several different types of cage, but all on wire floors $(\mathrm{r} \cdot 3 \mathrm{~cm}$ mesh). Most cages were of two types, cubes of side $90 \mathrm{~cm}$, and cages of triangular cross-section measuring $120 \mathrm{~cm}$ in length and of side $90 \mathrm{~cm}$.

\section{Management}

Variations occurred in the degree of disturbance to the birds from our own traffic past the cages, in the birds' condition and weight before breeding, and in the type of cage used.

To minimize the effect of these variables, hens were caged singly in blocks of three (1967) or two (r968), similar in age and weight at the end of the winter, and housed in adjacent cages of the same design, where disturbance was similar. One member of each block was assigned arbitrarily to each experimental treatment. The results were analysed by comparing the performance of pairs or trios of birds within each block.

An attempt had been made to do this experiment in 1966 , when birds were randomly paired at the end of the winter. As spring approached, the cocks became very aggressive and pecked the hens on the nape and back, killing several in a short time and damaging others. Results for the number of eggs laid could not therefore be used, but the hatchability of the eggs that were laid and the survival of the chicks hatched from them are presented (see Tables 3 and 4 ).

To avoid this trouble in 1967 , cocks were kept separate from the hens until just before laying started. One cock was rotated daily throughout each block of three hens and only the less aggressive cocks were used. A barrier behind which each hen could creep out of the cock's sight was put into each cage. The hens were much less damaged than in 1966 and only one was killed. However, this method of husbandry was followed by poor fertility $(78 \%)$ and very poor hatching ( $45 \%$ ) of the eggs (Table 3 ). Fertility $(89 \%)$ and hatching $(67 \%)$ had been quite good in 1966 , and the decrease was thought to be due to the change in husbandry.

A different approach was adopted in I968. Birds were either paired, or grouped with one cock to two hens in late 1967 . Cocks were moved around until each pair or group appeared to be well-adjusted to each other. The barriers behind which the hens could hide were retained. Hens which shared a cock were kept in separate halves of a cage with a sliding partition. The cocks were chivvied gently through the partition each day until they accepted this as a matter of routine, thus avoiding the continual disturbance caused in 1967 by catching the cocks.

As spring approached, some cocks became aggressive towards the hens, but at the 
first sign of any pecking the cocks' upper mandibles were trimmed. This generally halted the pecking, but two very aggressive birds had to be replaced by less aggressive individuals.

\section{Food}

The captive grouse were fed mainly on a diet of foods made by Joseph Rank Ltd, Caledonian Flour Mills, West Dock 6, Leith, Edinburgh: Blue Cross Grouse Maintenance Pellets in winter until mid-March and Grouse Breeders' Pellets in spring and early summer. The main feature of these diets, as compared with conventional poultry foods, is their high content of fibre ( 12 and I I \% respectively), designed to approximate to the high-fibre natural diet of grouse. The authors have inspected the detailed composition of these diets, kindly provided by the manufacturers. These details were confidential and cannot be published in full but, judging by what is known about the requirements of poultry, pheasants (Phasianus colchicus) and bobwhite quail (Colinus virginianus) (National Research Council, I960; Agricultural Research Council, 1963), the foods provided adequate amounts of every known nutrient - total protein, essential amino acids, minerals, and vitamins. These diets appeared to provide a much higher plane of nutrition than heather, as judged from chemical analyses of the heather (cf. Moss, 1967).

In addition to these pellets, the birds were given granite grit, limestone grit and water $a d l i b$., and a handful of heather in a bundle on alternate days. The heather constituted about $5 \%$ of the diet on the basis of dry weight. In the winter before each experiment, heather was cut in early March before it had started to grow, and was then stored in deep-freeze. This winter-cut dormant heather was fed to one randomly chosen bird in each block, and fresh, growing heather, cut every few days in spring, was fed to a second bird from late March onwards. In 1967 the third bird in each block was given no heather, and kept entirely on the artificial diet, but this treatment was not included in the 1968 experiment.

\section{Eggs}

Eggs were collected each day and stored at ro-13 $3^{\circ}$, blunt end up, in Keyes trays inclined at about $30^{\circ}$ to the horizontal. Each compartment in the trays had a little damp sand at the bottom and each tray was sprinkled with water and turned through I $80^{\circ}$ daily. Eggs were individually marked with a self-adhesive label.

Each week, eggs were set in clutches of eight under broody bantams. To minimize any effect of variation between bantams, eggs from each hen grouse were distributed among several different broodies. After $18 \mathrm{~d}$ incubation the eggs were removed from the bantams and put into still-air incubators at a temperature of $37^{\circ}$ at egg level. The relative humidity in these incubators was supposed to be $70 \%$, according to the manufacturers' specifications, but seldom rose above $50 \%$ even with additional water troughs; however, relative humidity of $35 \%$, measured with a hair-hygrometer, was quite adequate for hatching. Each egg was hatched in its own wire-mesh container, so that the origin of every chick was known. Chicks were ringed $24 \mathrm{~h}$ after hatching. 


\section{Rearing}

At $48 \mathrm{~h}$ of age chicks were put into brooder houses on the heather moor at Kerloch, with a floor area of $\mathrm{I} \cdot 2 \mathrm{~m} \times \mathrm{I} \cdot 2 \mathrm{~m}$. The floor was covered with $\mathrm{I} \cdot 3 \mathrm{~cm}$ wire mesh and the brooder house was placed on heather so that the heather tips projected through the floor. Heat, $35^{\circ}$ at chick level, was provided by a propane gas brooder (Maywick Appliances Ltd, Wickford, Essex).

The food given was Turkey Starter crumbs (The British Oil and Cake Mills, Ltd, I9 Blythswood Square, Glasgow). The chicks easily learned to take this light-coloured food when it was scattered over a dark surface, such as an upturned sod of peat. They began eating heather immediately. Water was provided in shallow dishes filled with stones for about a week and then, when the chicks were less likely to drown themselves, in conventional chick water-fountains. Granite grit was also given.

The brooder houses were moved twice a week on to fresh heather and a run $3 \mathrm{~m} \times 3 \mathrm{~m}$ was attached to each brooder house when the birds were about 2 weeks old.

\section{RESULTS}

\section{Number of eggs and rate of laying}

In both 1967 and 1968 the hens that were given a supplement of growing heather laid significantly more eggs (mean difference 12.4) than those given a supplement of dormant winter heather (Table I; $P<0.005$ in 1967, $P<0.025$ in 1968, $P<0.00$ I combining both years' results; using a $t$ test for paired variates). They also laid at a faster rate (Table 2; $P<0.025$ in each of the two years, $P<0.005$ combining the results). In 1967 the birds given no heather laid almost as many eggs as those given dormant heather, but fewer eggs than the group given growing heather $(P<0.025)$. There were not enough results to conclude anything about rate of laying in this group.

Differences between the groups receiving growing and dormant heather were less in 1968 than in 1967 . This difference between years was not significant for the number of eggs laid but was significant for the rate of laying $(P<0.025)$. This may have been due to chance, although in 1968 spring was late and the heather grew more slowly than in 1967 .

\section{Date of laying}

On average over both years, the birds that were getting a supplement of growing heather began to lay $4 \% 4 \mathrm{~d}$ earlier than those getting dormant heather (Table 2), but this effect was not significant $(0.2<P<0.4)$. With the observed variability (sE \pm 3.96) a difference of ro $d$ would have been necessary to attain a significant result.

There was no relation in either 1967 or 1968 between the weight of the hens up to mid-March and the number of eggs laid or the date of the birds' first egg. However, there was a significant relationship between weight on 28 March 1967 and both these variables (number of eggs, $r=0.429, P<0.02$; date, $r=0.61$ I,$P<0.01$ ). To rule out the effect of the type of heather, the number of eggs laid by each bird was expressed as a proportion of the mean number of eggs laid by each group. Hens that were heaviest 
at the end of March were presumably the most advanced in the physiological changes which precede egg-laying. (Birds were not weighed at the end of March I968.)

\section{Hatching}

The numbers of eggs hatched are given in Table 3 . Only results for the first ten eggs laid by each hen are considered here. Eggs laid late in the season tend to hatch less well than early eggs and the chicks from them survive less well than early chicks

Table I. Number of eggs laid by individual red grouse given an artificial diet either supplemented with winter $(W)$ or spring $(S)$ heather, or not supplemented $(N)$

\begin{tabular}{|c|c|c|c|c|}
\hline Year & $\begin{array}{c}\text { Block } \\
\text { no. }\end{array}$ & W & $\mathbf{S}$ & $\mathbf{N}$ \\
\hline \multirow[t]{12}{*}{ r 967} & $\mathbf{I}$ & II & 18 & \\
\hline & 2 & & 30 & 2 \\
\hline & 3 & r6 & 30 & $\circ$ \\
\hline & 4 & 19 & 19 & 0 \\
\hline & 5 & 9 & 35 & \\
\hline & 6 & I & 19 & 9 \\
\hline & 7 & I2 & 37 & 0 \\
\hline & & & & 13 \\
\hline & 9 & 6 & 21 & 14 \\
\hline & IO & 12 & & 20 \\
\hline & I I & I7 & 24 & \\
\hline & Mean & II 4 & 23.9 & $I I \cdot 6$ \\
\hline \multirow[t]{10}{*}{1968} & I & I 5 & 25 & \\
\hline & 3 & I & $20 \dagger$ & \\
\hline & 4 & 8 & $28 \dagger$ & \\
\hline & $\begin{array}{l}5 \\
6\end{array}$ & $\begin{array}{l}37 \\
24\end{array}$ & $\begin{array}{l}33 \\
22\end{array}$ & \\
\hline & 7 & $2 \mathrm{I}$ & 29 & \\
\hline & 8 & 15 & 34 & \\
\hline & Mean & $17 \cdot 3$ & $27 \cdot 3$ & \\
\hline & Mean difference & $\mathrm{W} v . \mathrm{S}$ & $\mathrm{W} v \cdot \mathrm{N}$ & $\mathrm{S}$ ข. $\mathrm{N}$ \\
\hline & $\begin{array}{l}1967 \\
1968\end{array}$ & $\begin{array}{l}14.0^{* *} \\
10.0^{*}\end{array}$ & $3 \cdot 8$ & $17 \cdot 7^{*}$ \\
\hline & $\begin{array}{l}\text { Both years } \\
\text { combined }\end{array}$ & $12 \cdot 4^{* * *}$ & & \\
\hline
\end{tabular}

* $P<0.05 ; \quad{ }^{*} P<0.01 ; \quad{ }^{* *} P<0.001$

$\dagger$ Birds died of egg peritonitis but none the less laid more eggs than their surviving partners.

No entry means that the bird died.

(H. Kolb, in preparation); this phenomenon is also well known in pheasants and partridges. If all eggs were included in the analysis, a bias lowering the hatching success and survival of eggs from hens which laid a large number of eggs would result. In any event, birds in the wild rarely lay more than ten eggs, so this might be regarded as a 'natural' clutch size for the captive birds also.

In 1968 there was some suggestion that the eggs laid by hens eating growing heather hatched better than eggs from hens on dormant heather (Table 3 ). This difference was statistically significant $\left(\chi^{2}=5 \cdot 49, P<0.05\right.$, excluding infertile eggs) when eggs 
Table 2. Comparison of the rate and period (expressed as number of days after 3 I March) of laying of individual red grouse given an artificial diet supplemented with winter $(W)$ or spring $(S)$ heather

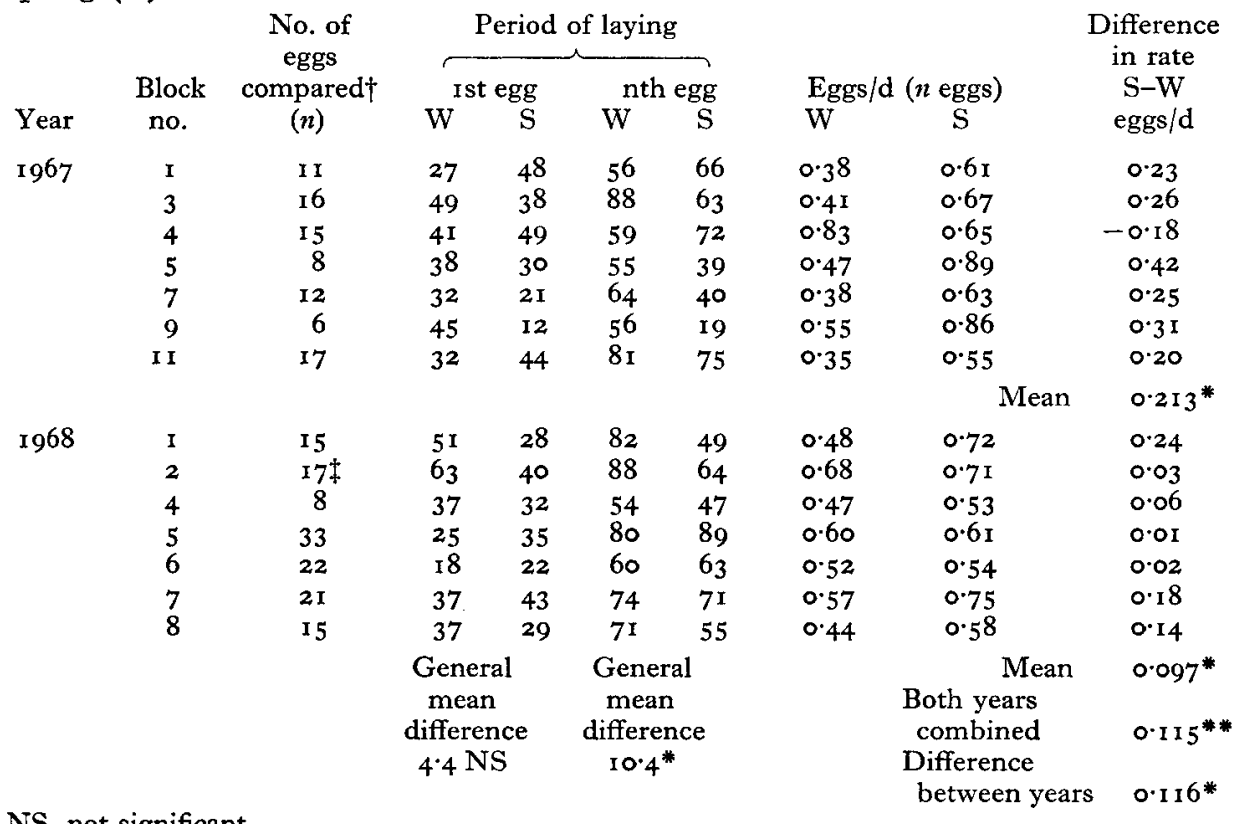

NS, not significant.

$* P<0.025 ; * * P<0.005$.

$\dagger$ Determined by the smallest number laid by one of a pair. Eggs laid later than 30 June are not included.

\$ This block is included here but not in Table I because the bird on winter heather died of egg peritonitis.

Table 3. Hatching of eggs laid by red grouse given an artificial diet either supplemented with winter $(W)$ or spring $(S)$ heather, or not supplemented $(N)$

\begin{tabular}{|c|c|c|c|c|c|c|c|}
\hline Year & $\begin{array}{l}\text { Type of } \\
\text { heather }\end{array}$ & $\begin{array}{l}\text { Incu- } \\
\text { bated }\end{array}$ & Hatched & Clear & $\begin{array}{c}\text { Clear } \\
(\%)\end{array}$ & $\begin{array}{l}\text { Fertile } \\
\text { eggs } \\
\text { hatched } \\
(\%)\end{array}$ & $\begin{array}{l}\text { No. of hens from } \\
\text { which eggs were taken } \\
\text { (range of eggs/hen) }\end{array}$ \\
\hline I966 & $\begin{array}{l}\mathrm{S} \\
\mathrm{W} \\
\mathrm{N}\end{array}$ & $\begin{array}{l}97 \\
71 \\
36\end{array}$ & $\begin{array}{l}65 \\
54 \\
17\end{array}$ & $\begin{array}{r}14 \\
6 \\
3\end{array}$ & $\begin{array}{r}15 \\
8 \\
8\end{array}$ & $\begin{array}{l}78 \\
83 \\
52\end{array}$ & $\begin{array}{r}\text { II }(2-10) \\
\text { I I }(2-10) \\
4(6-10)\end{array}$ \\
\hline & Total & 204 & 136 & 23 & I I & 75 & 26 \\
\hline I967 & $\begin{array}{l}S \\
W \\
N\end{array}$ & $\begin{array}{l}63 \\
68 \\
22\end{array}$ & $\begin{array}{r}30 \\
32 \\
7\end{array}$ & $\begin{array}{r}18 \\
8 \\
8\end{array}$ & $\begin{array}{l}26 \\
12 \\
36\end{array}$ & $\begin{array}{l}67 \\
53 \\
50\end{array}$ & $\begin{array}{r}12(\mathrm{I}-9) \\
\mathrm{I} 7(\mathrm{I}-9) \\
6(\mathrm{I}-5)\end{array}$ \\
\hline I968 & $\begin{array}{l}\text { Total } \\
\text { S } \\
\text { W }\end{array}$ & $\begin{array}{r}\mathrm{r} 53 \\
85 \\
87\end{array}$ & $\begin{array}{l}69 \\
61 \\
46\end{array}$ & $\begin{array}{l}34 \\
\text { I I } \\
\text { I } 5\end{array}$ & $\begin{array}{l}22 \\
13 \\
17\end{array}$ & $\begin{array}{l}58 \\
82 \\
64\end{array}$ & $\begin{array}{l}35 \\
10(7-10) \\
10(6-10)\end{array}$ \\
\hline & Total & 172 & 107 & 26 & I 5 & 73 & 20 \\
\hline
\end{tabular}

Results from only the first ten eggs laid by each hen are included. Values for 1966 are heterogeneous because many hens laid fewer than ten eggs, generally because they were killed or savaged by the cock while laying. Results from 1967 are heterogeneous because many bantams stood up while incubating in this year. The remaining sources of variation in no. of eggs/hen were due to accidental breakages and the fact that a few eggs had faulty shells and were not set. 
from all the hens on each diet were combined for the analysis. However, this difference was no longer significant when eggs from one hen whose eggs hatched very badly (one hatched out of seven fertile eggs) were excluded from the dormant heather group. There was a small and non-significant difference in the same direction in 1967 , but no difference in 1966 . The results therefore show no major difference in hatchability between eggs laid by hens on dormant and on growing heather, but do not exclude the possibility of a small difference.

However, in 1966 , eggs from hens given no heather hatched less well $(52 \%)$ than eggs from hens eating both winter and spring heather. This difference was significant $\left(\chi^{2}=10.56, P<0.005\right)$ when results for both blocks of hens which were given heather were combined (hatchability I I $9 / 148=80 \%$ ). A similar comparison for 1967 gives $\chi^{2}=0.13$ (not significant), but in that year the number of eggs from hens eating no heather was too small for the test to be sensitive. This result suggests that heather improved hatchability, though it mattered little whether the heather was dormant or growing.

\section{Survival of chicks}

The results given in Table 4 are more heterogeneous than we would wish. The 1968 figures are directly comparable with the hatching results for this year and only chicks from the first ten eggs laid by each bird are considered. However, the number of chicks reared in 1966 and 1967 from the first ten eggs of each bird by the method

Table 4. Survival of red grouse chicks to $\mathrm{r}$ month of age; the hens producing the chicks had been given artificial diets either supplemented with spring $(S)$ or winter $(W)$ heather or not supplemented $(N)$

$\begin{array}{cccc}\text { Year } & \text { Supplement } & \text { No. hatched } & \begin{array}{c}\text { Survival } \\ (\%)\end{array} \\ 1966 & \text { S } & 38 & 82 \\ & \text { W } & 36 & 75 \\ & \text { N } & 3 & 67 \\ & \text { Total } & 77 & 78 \\ 1967 & \text { S } & 24 & 71 \\ & \text { W } & 18 & 76 \\ & \text { N } & 5 & 40 \\ 1968 & \text { Total } & 47 & 72 \\ & \text { S } & 58 & 57 \\ & \text { W } & 41 & 44 \\ & \text { Total } & 99 & 52\end{array}$

described on p. ${ }^{1} 3^{8}$ was small, because this technique was still being compared with older methods described by Jenkins et al. (1965). The techniques were not comparable because the present method has proved to be more successful (R. Moss, R. A. Parr and N. Picozzi, unpublished). In order to provide a reasonable sample, results from all chicks reared by means of the new technique in 1966 and 1967 are given. This included chicks hatched from eggs laid after the first ten and so survival from the I966 and 1967 results was therefore probably poorer than it would have been if only early-hatched chicks had been included. 
Deaths in all 3 years occurred almost entirely in the first Io d. The same pattern was observed in deaths of chicks hatched from eggs laid by wild birds. Post-mortem examination showed no obvious cause of death in birds which died at this early stage. In contrast, deaths of older birds were almost always due to disease or accident. Table 4 shows survival to $30 \mathrm{~d}$; this period includes the first early wave of deaths but excludes the small number of deaths occurring later.

There was a slight difference in survival between chicks hatched from eggs laid by hens eating growing and dormant heather in 1968 (Table 4), but it was not statistically significant. There was no difference in 1967 or 1966 . Survival as a whole was very poor in $1968(52 \%)$ and compared unfavourably with survival in $1967(72 \%)$ and I $966(78 \%)$.

\section{DISCUSSION}

The poor survival of chicks in I 968 compared with that in 1966 and in 1967 (Table 4) was unlikely to have been due to poor nutrition because the same diets were given to the hens and to the chicks in each year. Even the possibility of a long-term depletion of some nutrient through several generations is unlikely, because four hens that had been hatched in 1967 from eggs of wild birds produced chicks in I 968 which survived as poorly (twelve out of twenty-two) as the chicks from captive parents (thirtynine out of seventy-seven). For the same reason, inbreeding of the stock may be excluded.

One possible reason is that aggressive cocks were prevented from breeding, because of the damage they did by attacking the hens. Thus, selection against aggressive cocks began in 1967 and continued in 1968 . The unaggressive birds which remained to breed may have produced offspring of low viability, although there are no results to support this suggestion.

A small proportion of growing heather in the diet stimulated captive red grouse to lay more eggs (Table I) and to lay at a faster rate (Table 2) than birds receiving dormant heather. This effect occurred although the birds were receiving apparently adequate amounts of all known nutrients. Work with mammals has provided similar observations. Newsome (1966) found it difficult to account for the speed with which wild red kangaroos (Megaleia rufa) responded to the appearance of green vegetation after rain in central Australia without invoking some dietary factor which stimulated breeding. Stodart \& Myers ( 1966 ) reported that rabbits (Oryctolagus cuniculus) in a large enclosure which were fed partly on oats bred better in a year when a shower caused the oats to germinate than in a year when it did not rain in the breeding season and the oats remained dry. Negus \& Pinter ( I 966) found that captive montane voles (Microtus montanus) produced more and larger litters when their dry diet was supplemented with germinating wheat, and with extracts of this wheat.

The growing heather had no consistent effect on the hatchability of the grouse eggs and the survival of the young produced. In other words, growing heather had little or no effect on the quality of the eggs. In this instance, the factor which stimulated breeding therefore acted unlike a nutrient, because deficiencies of known nutrients 
generally affect hatchability or survival, or both (National Research Council, I960; Agricultural Research Council, 1963). The effect produced by this factor was more like that of a hormone than of a nutrient.

In 1966 the hatchability of eggs from hens eating no heather was lower than that of eggs laid by hens given heather, combining the results from groups on dormant and newly growing heather. This suggests that the pelleted diet was inadequate in some respect, despite the fact that it contained adequate amounts of nutrients by standards applicable to poultry. Whatever the cause of this effect, it is unlikely to be of significance to wild red grouse, because their diet consists largely of heather.

It is also possible that the observed effect of growing heather on captive red grouse may have no relevance to the situation in the wild because most of the birds that received dormant heather laid enough eggs to produce an average clutch of eight (Table I), and because no effect on the date of laying was demonstrated (Table 2). However, under natural conditions the food of laying hens is largely heather. Thus the effects of newly growing material may be greater in the wild than noted here, because more of it is eaten. In addition, the plane of nutrition is lower in the wild than in the experiment, and interaction between the new-growth factor and plane of nutrition is possible.

In fact, there is a correlation between breeding success and the date of the first spring growth of heather in the wild (Jenkins et al. 1967). Generally, good breeding success is associated with earlier laying, more eggs per clutch and better chick survival than average. However, it is not clear what are the respective roles of the improvement in the plane of nutrition which accompanies new growth, and the new-growth factor discussed in this paper.

It is a pleasure to thank Dr D. Jenkins, Dr R. Kay, Dr G. R. Miller and Professor V. C. Wynne-Edwards for criticism of the manuscript and Mr H. E. Clarke for information about the composition of the artificial foods used.

\section{REFERENCES}

Agricultural Research Council (1963). The Nutrient Requirements of Farm Livestock. No. I. Poultry. London: H. M. Stationery Office.

Eastman, D. S. (1964). A comparative study of the food of the red grouse Lagopus lagopus scoticus based on faecal analysis. MSc Thesis, University of Aberdeen.

Jenkins, D., Watson, A. \& Miller, G. R. (1963). F. Anim. Ecol. 32, 317.

Jenkins, D., Watson, A. \& Miller, G. R. (1967). F. Anim. Ecol. 36, 97.

Jenkins, D., Watson, A. \& Picozzi, N. (1965). Trans Congr. int. Union Game Biol. vi, p. 63.

Moss, R. (1967). In Secondary Productivity of Terrestrial Ecosystems Vol. I, p. 369 [K. Petrusewicz, editor]. Warszawa and Krakow: Panstwowe Wydawnictwo Naukowe.

National Research Council (ig60). Publs natn. Res. Coun., Wash. no. 827.

Negus, N. C. \& Pinter, A. J. (1966). F. Mammal. 47, 596.

Newsome, A. E. (1966). C.S.I.R.O. Wildl. Res. 11, I87.

Stodart, E. \& Myers, K. (1966). C.S.I.R.O. Wildl. Res. II, I I I.

Wilson, E. A. (I9I ). In The Grouse in Health and in Disease, Being the Final Report of the Committee of Enquiry on Grouse Disease p. 67. London: Elder. 